\title{
Perancangan Sistem Pengaturan Suhu Kandang Ayam Berbasis Mikrokontroler
}

\author{
Rio Krismas Sebayang ${ }^{1)}$, Osea Zebua ${ }^{2)}$, Noer Soedjarwanto ${ }^{3)}$ \\ ${ }^{1,2,3)}$ Jurusan Teknik Elektro Universitas Lampung \\ Jl. Prof. Sumantri Brojonegoro No. 1 Bandar Lampung 35145 \\ riochris15@gmail.com
}

\begin{abstract}
ABSTRAK
Ayam broiler merupakan hewan ternak yang pertumbuhannya dipengaruhi oleh suhu lingkungan.Suhu kandang ayam yang tidak sesuai dapat mempengaruhi penurunan produktivitas dan menyebabkan kematian pada ayam broiler, sehingga pengaturan suhu kandang harus dilakukan.

Perancangan sistem pengaturan suhu otomatis ini menggunakan mikrokontroler Atmega 8535 sebagai pengendali utama, LM35 sebagai sensor suhu pada kandang dan IC L293D sebagai driver motor DC. Mikrokontroler akan memerintahkan motor DC untuk bekerja, apabila suhu yang terukur diatas dari batasan suhu yang ditetapkan dan akan memerintahkan relay untuk menyalakan atau mematikan lampu pijar apabila suhu yang terukur dibawah dari batasan suhu yang telah ditentukan.

Hasil penelitian menunjukkan bahwa peralatan pengaturan suhu kandang ayam secara otomatis ini dapat bekerja dengan baik untuk mengatur suhu kandang ayam secara otomatis.
\end{abstract}

Kata kunci :pengaturan suhu otomatis, kandang ayam, mikrokontroler, sensor temperatur

\section{ABSTRACT}

Broilers chicken are animals whose growth is affected by ambient temperature. The temperature of the chicken coop that does not fixed can affect a decrease in productivity and causes the death of broiler chickens, so theenclosuretemperature settingshouldbe done.

Automatic temperature control system design uses ATmega8535 microcontroller as the main controller, LM35 as temperature sensor on the cage and IC L293D as a DC motor driver. The microcontroller will command a DC motor to work, if the measured temperature above the limits of setting temperature and will command relay to light up or turn off the lamp when the measured temperature is below the predetermined temperature limits.

The results showed that this automatic equipment can work well to regulate the temperature of the chicken coop automatically.

Keywords : automatic temperature control, chicken coop, microcontroller, temperature sensor

\section{PENDAHULUAN}

Ayam broiler merupakan jenis ayam hasil dari budidaya teknologi peternakan yang memiliki ciri khas pertumbuhan yang cepat, sebagai penghasil daging dengan konversi pakan yang rendah dan siap dipotong pada usia 28-45 hari. Dalam beternak ayam yang perlu diperhatikan antara lain pemberian pakan ayam yang seimbang dan suhu kandang ayam yang sesuai. Ayam merupakan termasuk hewan berdarah panas (endotermik) yang suhu tubuhnya diatur suatu batasan yang sesuai. Ayam dapat bereproduksi secara optimum bila faktor-faktor internal dan eksternal berada dalam batasan-batasan yang normal sesuai dengan kebutuhan hidupnya.Suhu lingkungan merupakan salah satu faktor eksternal yang dapat mempengaruhi produktivitas ayam. Suhu panas pada suatu lingkungan pemeliharaan ayam telah menjadi salah satu perhatian utama karena dapat menyebabkan kerugian ekonomi akibat peningkatan kematian dan penurunan produktivitas. Keadaan suhu yang relatif tinggi pada suatu lingkungan pemeliharaan menyebabkan terjadinya cekaman panas. Cekaman panas menyebabkan gangguan terhadap pertumbuhan ayam broiler. Gangguan pertumbuhan ini terkait dengan penurunan konsumsi pakan dan peningkatan konsumsi air minum selama ayam mengalami cekaman panas.

Dalam rangka menjawab tantangan tersebut, peternak ayam diharuskan memilih metodemetode yang tepat guna untuk pemeliharaan 
ayam. Metode-metode itu antara lain metode pemilihan lahan, metode pembuatan kandang, metode pemberian pakan, metode pembersihan kandang. Salah satu solusi untuk mengatasi permasalahan tersebut adalah pemanfaatan teknologi. Oleh karena itu, penulis mencoba untuk merancang suatu kandang ayam dengan sistem otomasi untuk membantu dan mendukung peternak dalam bidang pemeliharaan terutama dalam pengaturan suhu kandang ayam. Alat ini diharapkan dapat membantu peternak dalam mengurangi kematian atau penurunan produktivitas ayam ternak akibat kenaikan suhu lingkungan sekitar.Acuan utama yang digunakan adalah penggunaan mikrokontroler Atmega8535 seri AVR sebagai pengontrol utama dari sistem.

\section{TINJAUAN PUSTAKA}

\subsection{Ayam Broiler}

Ayam broiler atau ayam pedaging adalah ayam yang mempunyai kemampuan hidup yang tinggi dan mampu mengubah pakan menjadi daging secara efisien. Pada umumnya ayam ini siap panen pada usia 28-45 hari dengan berat badan 1,2-2 kg/ekor.

Suhu lingkungan mempengaruhi pertumbuhan ayam.Pada prinsipnya pertumbuhan dan efisiensi penggunaan makanan yang maksimum tidak dapat dicapai, bila ayam dipelihara di bawah atau di atas suhu lingkungan yang tidak sesuai. Pada suhu $34{ }^{\circ} \mathrm{C}$, ayam mengalami kesulitan dalam membuang panas, terutama jika dikuti dengan kelembaban yang tinggi dalam keadaan demikian ayam tidak dapat lagi membuang panasnya, sehingga suhu tubuh cenderung melambung. Pada saat hewan sudah tidak mampu lagi mempertahankan homeoterm, hewan akan mereduksi produksi panas dengan menggunakan mekanisme fisiologis internal untuk mengupayakan pengaturan keseimbangan panas menjadi lebih baik kembali. Komsumsi pakan dan sekresi hormon termogenik akan mengalami penurunan untuk mengurangi metabolisme basal yang akan diikuti dengan adanya penurunan produktivitas. Jika semua mekanisme fisiologis tersebut gagal untuk memperbaiki atau mengembalikan keseimbangan muatan panas tubuh maka suhu tubuh hewan akan meningkat dan hewan tersebut memasuki fase akut. Jika sistem tersebut juga masih gagal maka fase selanjutnya akan dapat mengakibatkan kematian.Tabel 2.1 menunjukkan suhu nyaman bagi ayam broiler pada tingkat umur yang berbeda-beda.

Tabel 2.1. Suhu yang nyaman bagi ayam

\begin{tabular}{|c|c|}
\hline Umur ( Hari ) & Suhu $\left({ }^{\circ} \mathrm{C}\right.$ ) \\
\hline 1 & $32-29$ \\
\hline 3 & $30-27$ \\
\hline 6 & $28-25$ \\
\hline 9 & $27-25$ \\
\hline$>12$ & $26-24$ \\
\hline
\end{tabular}

\subsection{Mikrokontroler}

Mikrokontroler merupakan suatu perangkat elektronika digital berupa IC(Integrated Circuit) yang dapat menerima sinyal input, mengolahnya dan memberikan sinyal output yang dikendalikan oleh program yang bisa ditulis dapat dihapus secara khusus. Mikrokontroler pada dasarnya adalah komputer dalam satu chip, yang di dalamnya terdapat mikroprosesor, memori, jalur Input/Output (I/O) dan perangkat pelengkap lainnya.

Pada tugas akhir ini digunakan salah satu jenis mikrokontroler keluarga AVR (Alf and Vegard's Risc Processor) yang diproduksi oleh Atmel Corporation dikarenakan mikrokontroler ini memiliki fitur-fitur menarik dan fasilitas yang lengkap selain mudah didapatkan dan harga relatif murah. Mikrokontroler ini merupakan seri mikrokontroler vCMOS 8-bit buatan Atmel yang memiliki daya rendah dalam pengoperasiannya dan berbasis pada arsitektur RISC (Reduced Instruction Set Computer). Hampir semua instruksi dieksekusi dalam satu siklus clock, dan dapat mencapai 1 MIPS per MHz, sehingga para perancang dapat mengoptimalkan penggunaan daya rendah dengan kecepatan yang tinggi. Mikrokontroler ini mempunyai 32 register general purpose, timer/counter fleksibel dengan mode compare, interrupt internal dan eksternal, serial UART, programmable Watchdog Timer, dan modepower saving. Memiliki ADC dan PWM internal, memiliki In-System Programmable Flash on-chip yang mengijinkan memori program untuk diprogram ulang dalam sistem menggunakan hubungan serial SPI. 


\subsection{LCD (Liquid Crystal Display)}

LCD merupakan suatu jenis penampil (display) yang menggunakan Liquid Crystal sebagai media refleksinya.LCD juga sering digunakan dalam perancangan alat yang menggunakan mikrokontroler. LCD dapat berfungsi untuk menampilkan suatu nilai hasil sensor atau menampilkan menu pada aplikasi mikrokontroler. Tergantung dengan perintah yang ditulis pada mikrokontroler.

\subsection{Sensor Suhu}

Sensor suhu LM35 memiliki keakuratan tinggi, yang tegangan keluarannya linier dan dalam satuan Celcius. Sensor LM35 memiliki kelebihan dibandingkan dengan sensor suhu yang lain. Sensor LM35 mempunyai keluaran impedansi yang rendah, linieritas yang tinggi dan sifat ketepatan dalam pengujian membuat proses interface untuk membaca dan mengontrol sirkuit lebih mudah. Sehingga dapat dengan mudah dihubungkan dengan rangkaian kendali khusus serta tidak memerlukan penyetelan lanjutan.

\subsection{IC L293D}

IC L293D adalah IC yang didesain khusus sebagai driver motor DC dan dapat dikendalikan dengan rangkaian TTL maupun mikrokontroler. Motor DC yang dikontrol dengan driver IC L293D dapat dihubungkan ke ground maupun ke sumber tegangan positif karena di dalam L293D sistem driver yang digunakan adalah totem pool. Dalam 1 unit chip IC L293D terdiri dari 4 buah driver motor DC yang berdiri sendiri dengan kemampuan mengalirkan arus 1 Ampere tiap drivernya. Sehingga dapat digunakan untuk membuat driver $\mathrm{H}$-bridge untuk 2 buah motor DC.

\subsection{Relay}

Relay adalah sebuah peralatan listrik yang berfungsi sebagai saklar (switch), relay bekerja pada saat coil relay diberikan tegangan atau arus. Pada saat coil diberikan arus maka pada inti coil akan menjadi magnet yang kemudian menarik kontak-kontak penghubung pada relay tersebut. Pada relay terdapat dua buah kontak yang berbeda yakni kontak NO (Normaly Open) dan NC (Normaly Close). Pada saat kumparan coil belum diberikan arus keadaan kontak $N O$ akan terbuka dan pada saat kumparan coil diberikan arus kontak NO akan terhubung. Untuk kontak NC (Normaly Close) pada saat kumparan coil belum diberikan arus kontak NC belum terhubung dan pada saat kumparan coil dialiri arus maka kontak NC menjadi dalam kondisi terhubung.

\subsection{Relay}

Energi listrik adalah energi utama yang dibutuhkan bagi peralatan listrik. Energi listrik untuk menggerakkan motor, lampu penerangan, memanaskan, mendinginkan ataupun untuk menggerakkan kembali suatu peralatan mekanik untuk menghasilkan bentuk energi yang lain.

Besar energi listrik tersebut dirumuskan sebagai berikut:

$\mathrm{W}=\mathrm{P} \times \mathrm{t}$

\section{METODOLOGI PENELITIAN}

Pada Perancangan Sistem Pengaturan Suhu Kandang Ayam Berbasis Mikrokontroler ini terdiri dari dua bagian yaitu perancangan perangkat keras dan pembuatan program.

\subsection{Blok Diagram Sistem}

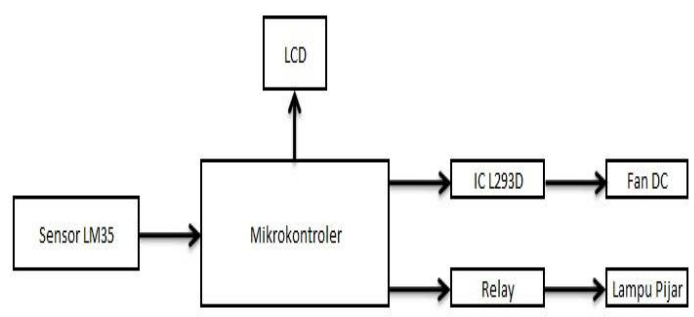

Gambar 3.1 Blok Diagram Sistem.

\subsection{Perancangan Perangkat Keras}

\section{a. Rangkaian Sensor}

Rangkaian sensor suhu ini berfungsi sebagai pendeteksi suhu kandang ayam.Sensor LM35 bekerja dengan cara merasakan atau mendeteksi keadaan suhu sekitar menjadi tegangan analog pada pin A. Pada setiap perubahan suhu per $1^{0}=$ $10 \mathrm{mV}$. Tegangan output inilah yang menjadi sumber inputan pada mikrokontroler. 


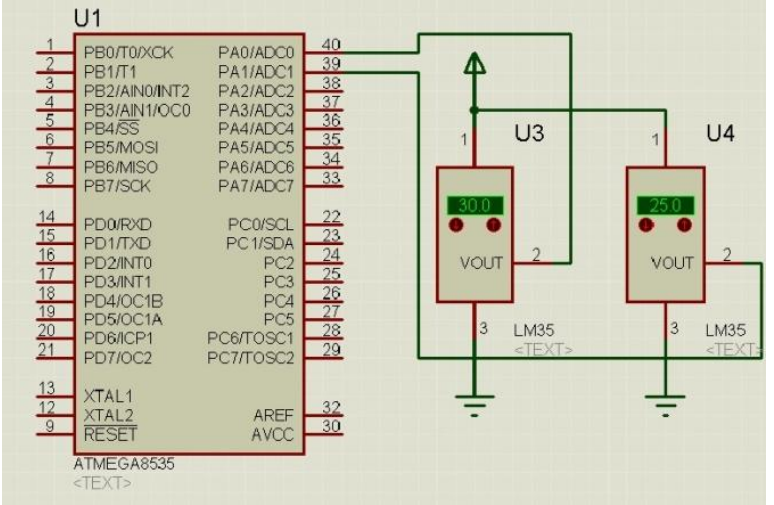

Gambar 3.2 Rangkaian sensor LM35.

\section{b. Rangkaian Pengendali}

Rangkaian pengendali ini menggunakan mikrokontroler Atmega8535 yang memiliki fitur membaca nilai output dari rangkaian sensor suhu. Pin yang digunakan pada Atmega8535 ini sebagai input adalah pin A, yang merupakan pin untuk ADC, dan pin outputnya adalah pin B untuk driver lampu pijar dan pin $\mathrm{D}$ untuk driver kipas. Sedangkan Pin C digunakan untuk LCD.

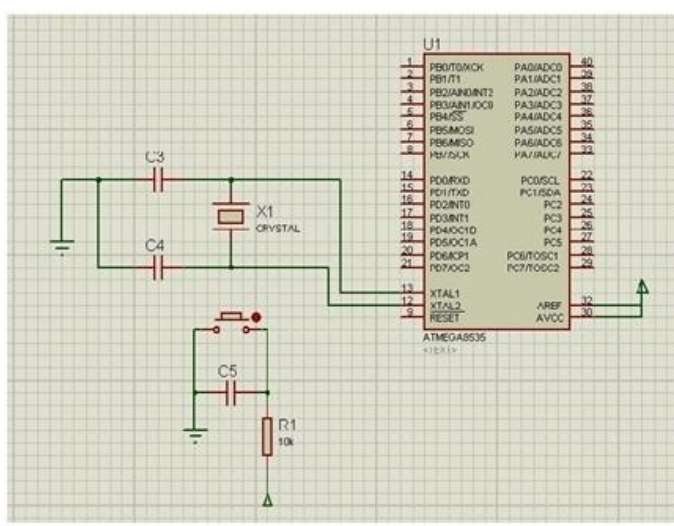

Gambar 3.3 Rangkaian sistem minimum mikrokontroler

\section{c. Rangkaian Heater}

Pemanasan pada kandang ini akan menggunakan lampu pijar agar lebih efisien. Lampu pijar berfungsi menaikkan suhu apabila terjadi penurunan suhu dari setting poin yang diinginkan.Pemanasan menggunakan lampu pijar tidak berpengaruh terhadap kondisi ayam broiler karena kenaikan suhu tidak terjadi secara signifikan. Pemasangan lampu ditempatkan pada titik tertentu agar pemanasan dapat merata.

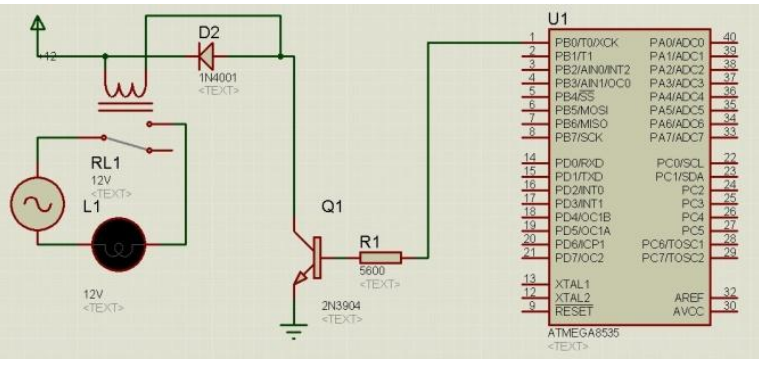

Gambar 3.4 Rangkaian heater

\section{d. Rangkaian Kipas DC}

Kipas / blower yang digunakan berjumlah 2 buah yang diletakkan pada kandang ayam.Rangkaian kipas ini berfungsi untuk menurunkan suhu kandang ayam jika melebihi dari setting poin yang diinginkan. Dengan menggunakan dua buah kipas diharapkan mampu mengontrol suhu kandang agar terhindar yang dari kenaikan suhu yang sangat cepat.

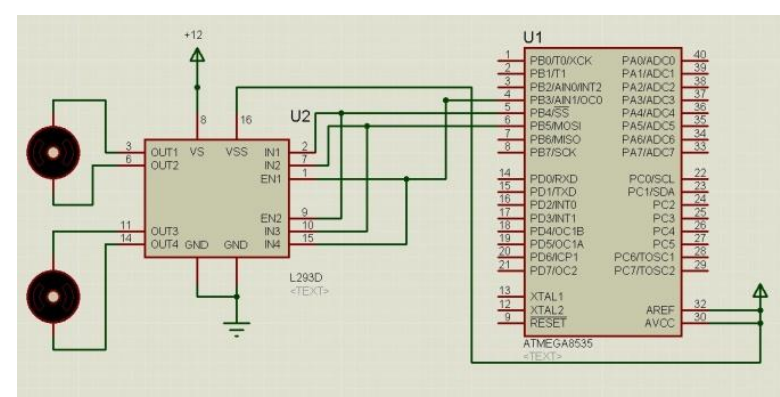

Gambar 3.5 Rangkaian kipas DC

\section{e. Rangkaian LCD}

$L C D$ digunakan untuk menampilkan data-data yang terdapat pada mikrokontroller. LCD dalam rangkaian ini akan menampilkan nilai suhu yang terbaca pada pin input ADC.

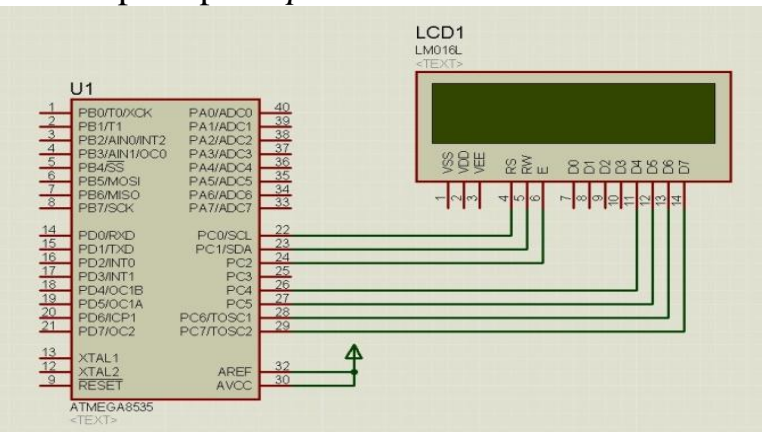

Gambar 3.6 Rangkaian LCD

\subsection{Pembuatan Program}

Perangkat lunak yang digunakan untuk memprogram mikrokontroler menggunakan 
bahasa pemrograman $\mathrm{C}$ pada software Code Vision AVR.

Adapun langkah-langkah dalam pembuatan program dapat dilihat pada gambar 3.6 berikut

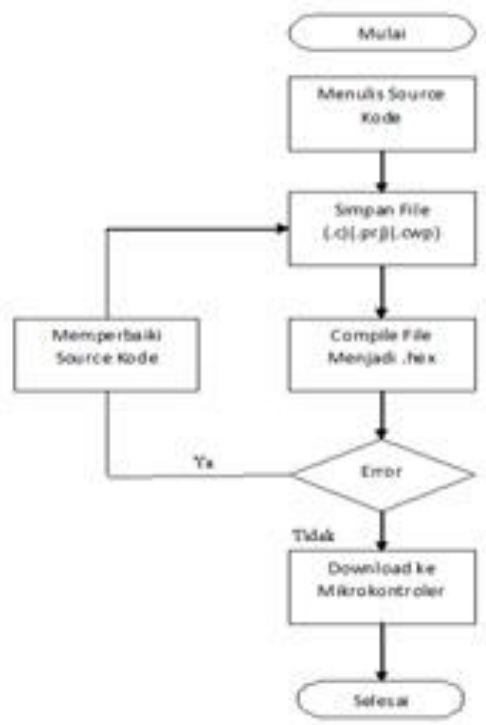

Gambar 3.6 Diagram alir pembuatan program.

\section{HASIL DAN PEMBAHASAN}

Rangkaian ini bekerja untuk mendeteksi nilai suhu pada kandang ayam dan menghidupkan pemanas atau kipas apabila besar nilai suhu yang didapatkan kurang atau melebihi daari besaran nilai suhu yang telah ditentukan.

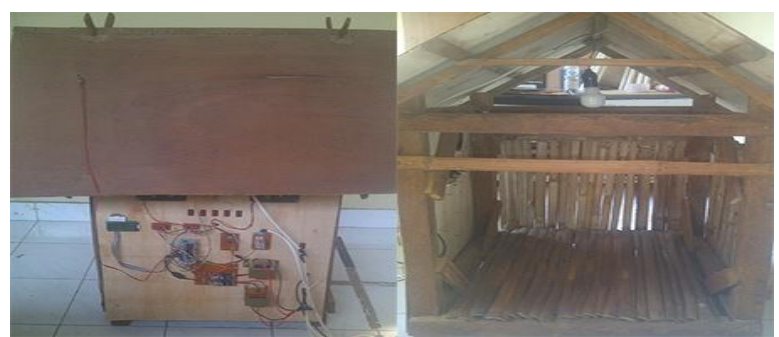

Gambar 4.1 Kandang ayam.

\subsection{Pengujian Perangkat Keras}

Pengujian ini dilakukan bertujuan agar kita dapat mengetahui kinerja masing-masing perangkat dapat bekerja dengan baik. Adapun perangkat keras yang diuji antara lain rangkaian pengendali utama, rangkaian power supply, sensor suhu, $\mathrm{LCD}$, rangkaian relay dan driver motor DC

\section{a. Rangkaian Pengendali Utama}

Pengujian terhadap pengendali utama bertujuan untuk mengetahui apakah mikrokontroler tersebut dapat bekerja dengan baik atau tidak. Pengujian pengendali utama ini dilakukan dengan mengecek seluruh pin input dan output yang ada pada mikrokontroler.

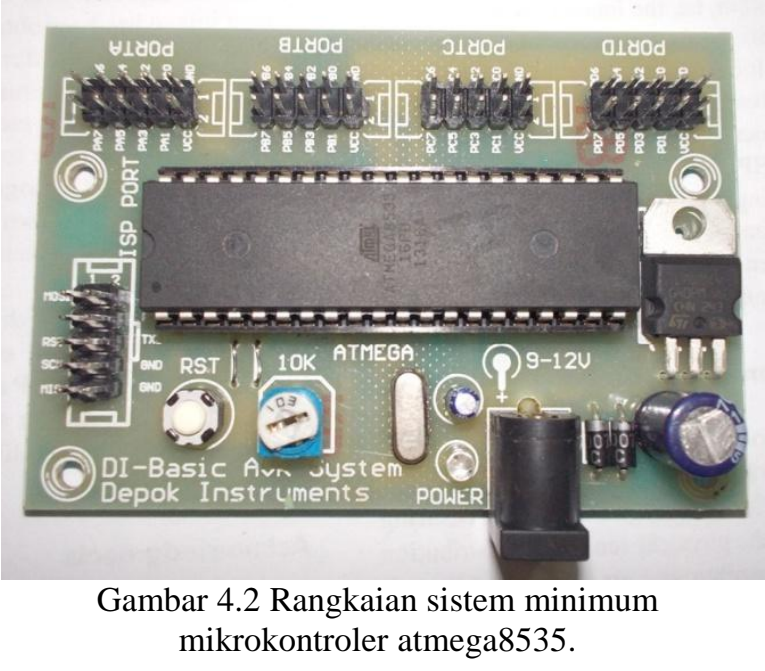

Tabel 4.1 Hasil pengujian pengukuran tegangan pada mikrokontroler.

\begin{tabular}{|c|c|}
\hline $\begin{array}{c}\text { Mikrokontroler Atmega8535 } \\
\text { (Pada PORTB.0) }\end{array}$ & Tegangan \\
\hline Logika High & $5 \mathrm{~V}$ \\
\hline Logika Low & 0 V \\
\hline
\end{tabular}

\section{b. Sensor Suhu LM35}

Sensor suhu LM35 ini mengubah besaran suhu menjadi besaran tegangan dengan keluaran $0 \mathrm{mV}$ saat suhu $0{ }^{\circ} \mathrm{C}$ dan $1000 \mathrm{mV}$ DC saat suhu $100^{\circ} \mathrm{C}$. Dengan demikian setiap kenaikan $1{ }^{\circ} \mathrm{C}$ yang terbaca sensor suhu LM35 memberikan kenaikan tegangan keluaran sebesar 10mV DC.

Tabel 4.2 Nilai Suhu yang Terukur Termometer Digital dan LM35

\begin{tabular}{|c|c|c|}
\hline Sensor Suhu 1 & Sensor Suhu 2 & Termometer digital \\
\hline $27,8^{\circ} \mathrm{C}$ & $27,8^{\circ} \mathrm{C}$ & $28^{\circ} \mathrm{C}$ \\
\hline $28,8^{\circ} \mathrm{C}$ & $28,8^{\circ} \mathrm{C}$ & $29,1^{\circ} \mathrm{C}$ \\
\hline $29,4^{\circ} \mathrm{C}$ & $29,4^{\circ} \mathrm{C}$ & $29,8^{\circ} \mathrm{C}$ \\
\hline $29,2^{\circ} \mathrm{C}$ & $29,2{ }^{\circ} \mathrm{C}$ & $29,8^{\circ} \mathrm{C}$ \\
\hline $28,5^{\circ} \mathrm{C}$ & $28,5^{\circ} \mathrm{C}$ & $29,2^{\circ} \mathrm{C}$ \\
\hline
\end{tabular}

\section{c. LCD}

Pengujian $L C D$ bertujuan untuk mengetahui apakah $L C D$ yang akan digunakan dapat bekerja dengan baik menampilkan karakter yang 
diinginkan atau tidak. Pengujian LCD dilakukan dengan cara menghubungkan masing-masing pin pada $L C D$ tersebut ke PORTC mikrokontroler.

Setelah kaki-kaki $L C D$ terhubung, pengendali utama diprogram untuk menampilkan karakter. Apabila karakter yang ditampilkan pada $L C D$ sesuai dengan karakter yang diprogram pada mikrokontroler, maka $L C D$ bekerja dengan baik.

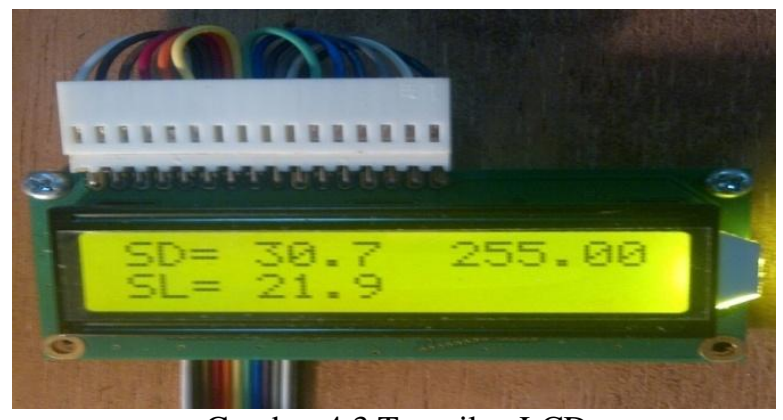

Gambar 4.3 Tampilan LCD.

\section{d. Rangkaian Relay}

Pada saat tegangan output dari mikrokontroler sebesar $0 \mathrm{~V}$ maka transistor akan berfungsi sebagai saklar posisi mati maka relay pada rangkaian ini beerada pada kondisi off. Sebaliknya jika tegangan output dari mikrokontroler sebesar 5 volt maka transistor akan berfungsi sebagai saklar posisi on maka relay pada rangkaian ini akan berada pada kondisi on.

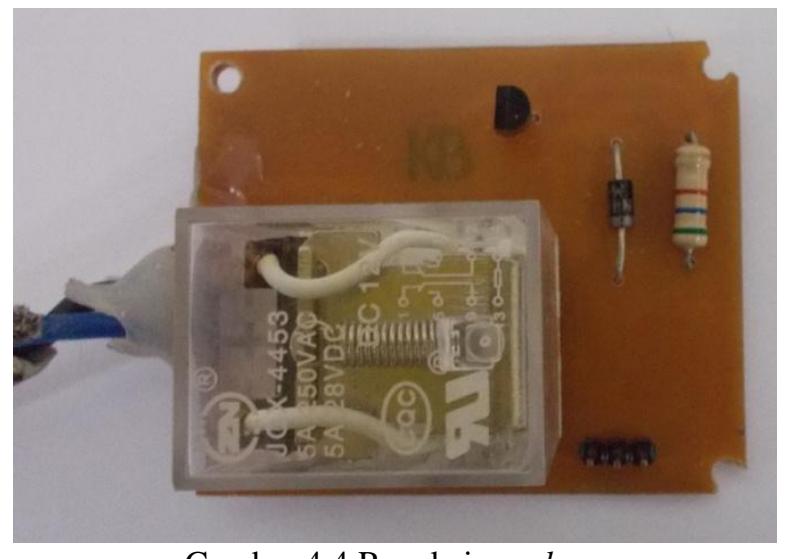

Gambar 4.4 Rangkaian relay.

\section{e. Rangkaian Driver Motor}

Driver motor yang digunakan adalah menggunakan IC 1293D untuk mengontrol putaran motor DC.

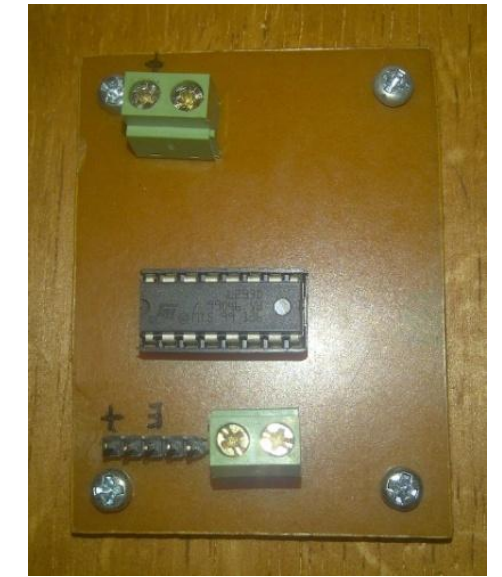

Gambar 4.5 Rangkaian driver motor.

Penggunaan IC L293D dapat mengendalikan dua buah motor secara bersamaan. Apabila masukan pada IC L293D high maka keluarannya pun akan high, begitu juga sebaliknya, apabila masukannya low maka outputnya akan low, dengan syarat input enable harus diberi logika high.

\subsection{Pengujian Alat}

Pada rangkaian ini terdapat 5 saklar yang berfungsi memberikan masukan high atau low pada mikrokontroler. Saklar berfungsi untuk menentukan batasan suhu yang digunakan untuk memberi perintah kepada mikrokontroller, agar dapat bekerja menjaga kestabilan suhu kandang sesuai dengan nilai batasan suhu yang telah ditentukan. Penentuan batasan suhu berdasarkan umur dan suhu nyaman yang bagi ayam.

Tabel 4.3 Saklar dan Batasan Suhu

\begin{tabular}{|c|c|c|}
\hline Saklar & Batasan Suhu & Umur Ayam( Hari ) \\
\hline Saklar 1 & $24-26$ & $>12$ \\
\hline Saklar 2 & $25-27$ & 9 \\
\hline Saklar 3 & $25-28$ & 6 \\
\hline Saklar 4 & $27-30$ & 3 \\
\hline Saklar 5 & $29-32$ & 1 \\
\hline
\end{tabular}

Hasil pengukuran suhu kandang menggunakan LM35 adalah sebagai berikut :

a. Batasan Suhu 24-26 
Tabel 4.4. Hasil Pengukuran Suhu Dengan Batasan Suhu $24-26^{\circ} \mathrm{C}$

\begin{tabular}{|c|c|c|c|}
\hline $\begin{array}{c}\text { Pukul } \\
\text { (WIB) }\end{array}$ & $\begin{array}{c}\text { Suhu Lingkungan } \\
\left({ }^{\circ} \mathrm{C}\right)\end{array}$ & $\begin{array}{c}\text { Suhu Kandang } \\
\left({ }^{\circ} \mathrm{C}\right)\end{array}$ & Keterangan \\
\hline 00.00 & 26 & 25.5 & - \\
\hline 03.00 & 24.5 & 25 & - \\
\hline 06.00 & 26.5 & 25.5 & Kipas Hidup \\
\hline 09.00 & 28 & 26 & Kipas Hidup \\
\hline 12.00 & 31.2 & 28.4 & Kipas Hidup \\
\hline 15.00 & 29.4 & 28 & Kipas Hidup \\
\hline 18.00 & 28.4 & 26.9 & Kipas Hidup \\
\hline 21.00 & 27 & 25.5 & Kipas Hidup \\
\hline \multicolumn{4}{|r|}{} \\
\hline
\end{tabular}

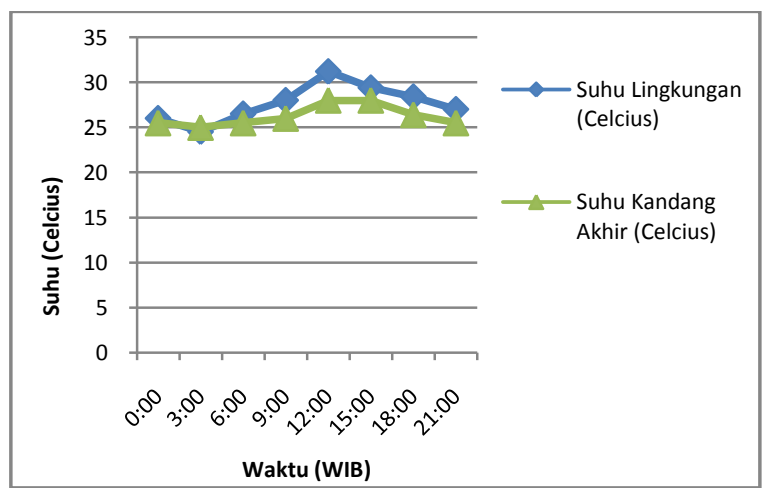

Gambar 4.6 Grafik Hasil Pengukuran Suhu Dengan Batasan Suhu $24-26{ }^{\circ} \mathrm{C}$.

Dari tabel 4.4 dan gambar 4.6 terlihat suhu kandang dapat terjaga antara kisaran suhu $26{ }^{\circ} \mathrm{C}$ sampai $25{ }^{\circ} \mathrm{C}$. Hanya pada kisaran jam 12.00 WIB siang sampai 15.00 WIB suhu kandang mencapai suhu $28.4{ }^{\circ} \mathrm{C}$ dan $26.9{ }^{\circ} \mathrm{C}$. Hal ini disebabkan besarnya nilai suhu lingkungan sangat mempengaruhi suhu pada kandang sehingga kipas tidak dapat menjaga suhu kandang pada besaran nilai suhu yang ditentukan. Lampu akan secara otomatis hidup saat suhu kandang berada dibawah suhu $24{ }^{\circ} \mathrm{C}$ dan lampu akan mati secara otomatis ketika suhu mencapai nilai suhu diatas $25{ }^{\circ} \mathrm{C}$. Sedangkan kipas akan hidup secara otomatis hidup saat suhu kandang berada diatas suhu $26{ }^{\circ} \mathrm{C}$ dan akan mati secara otomatis ketika suhu mencapai nilai suhu $25{ }^{\circ} \mathrm{C}$.

b. Batasan Suhu 25-27

Tabel 4.5. Hasil Pengukuran Suhu Dengan Batasan Suhu $25-27^{\circ} \mathrm{C}$

\begin{tabular}{|c|c|c|c|}
\hline $\begin{array}{c}\text { Pukul } \\
\text { (WIB) }\end{array}$ & $\begin{array}{c}\text { Suhu } \\
\text { Lingkungan }\left({ }^{\circ} \mathrm{C}\right)\end{array}$ & $\begin{array}{c}\text { Suhu Kandang } \\
\left({ }^{\circ} \mathrm{C}\right)\end{array}$ & Keterangan \\
\hline 00.00 & 26 & 26.4 & - \\
\hline 03.00 & 24.5 & 25.9 & Lampu Hidup \\
\hline 06.00 & 26.5 & 25.9 & - \\
\hline 09.00 & 28 & 26 & Kipas Hidup \\
\hline 12.00 & 31.2 & 28.4 & Kipas Hidup \\
\hline 15.00 & 29.4 & 27.9 & Kipas Hidup \\
\hline 18.00 & 28.4 & 26.4 & Kipas Hidup \\
\hline 21.00 & 27 & 25.9 & Lampu Hidup \\
\hline
\end{tabular}

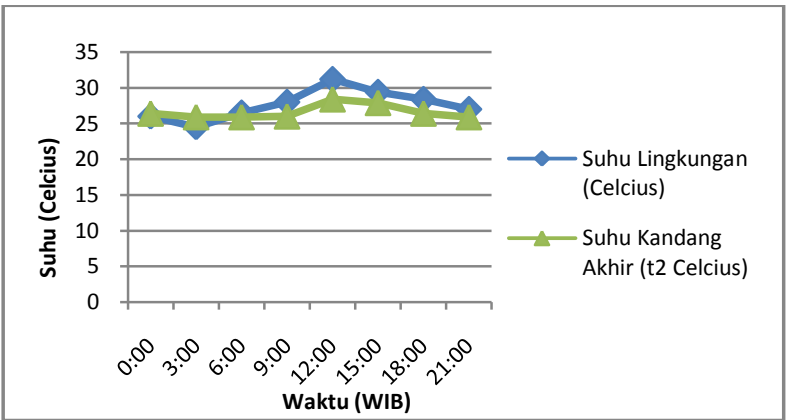

Gambar 4.7 Grafik Hasil Pengukuran Suhu Dengan Batasan Suhu $27-25^{\circ} \mathrm{C}$

Dari tabel 4.5 dan gambar 4.7 terlihat suhu kandang dapat terjaga antara kisaran suhu $27{ }^{\circ} \mathrm{C}$ sampai $25{ }^{\circ} \mathrm{C}$. Hanya pada kisaran jam 12.00 WIB siang sampai 15.00 WIB suhu kandang mencapai suhu $28.4{ }^{\circ} \mathrm{C}$ dan $26.9{ }^{\circ} \mathrm{C}$. Hal ini disebabkan besarnya nilai suhu lingkungan sangat mempengaruhi suhu pada kandang sehingga kipas tidak dapat menjaga suhu kandang pada besaran nilai suhu yang ditentukan. Lampu akan secara otomatis hidup saat suhu kandang berada dibawah suhu $25{ }^{\circ} \mathrm{C}$ dan lampu akan mati secara otomatis ketika suhu mencapai nilai suhu diatas $26{ }^{\circ} \mathrm{C}$. Sedangkan kipas akan hidup secara otomatis hidup saat suhu kandang berada diatas suhu $27{ }^{\circ} \mathrm{C}$ dan akan mati secara otomatis ketika suhu mencapai nilai suhu $25^{\circ} \mathrm{C}$.

c. Batasan Suhu 25-28

Tabel 4.6. Hasil Pengukuran Suhu Dengan Batasan Suhu $28-25^{\circ} \mathrm{C}$

\begin{tabular}{|c|c|c|c|}
\hline $\begin{array}{c}\text { Pukul } \\
(\text { WIB })\end{array}$ & $\begin{array}{c}\text { Suhu } \\
\text { Lingkungan }\left({ }^{\circ} \mathrm{C}\right)\end{array}$ & $\begin{array}{c}\text { Suhu Kandang } \\
\left({ }^{\circ} \mathrm{C}\right)\end{array}$ & Keterangan \\
\hline 00.00 & 26 & 26.4 & - \\
\hline 03.00 & 24.5 & 26.4 & Lampu Hidup \\
\hline 06.00 & 26.5 & 25.9 & - \\
\hline 09.00 & 28 & 26.9 & Kipas Hidup \\
\hline 12.00 & 31,2 & 28.4 & Kipas Hidup \\
\hline 15.00 & 29.4 & 27.9 & Kipas Hidup \\
\hline 18.00 & 28.4 & 26.4 & Kipas Hidup \\
\hline 21.00 & 27 & 26.9 & - \\
\hline
\end{tabular}

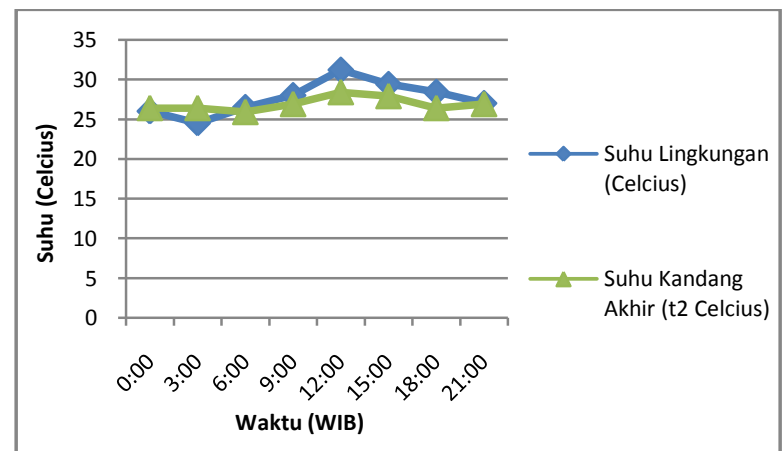

Gambar 4.8 Grafik Hasil Pengukuran Suhu Dengan Batasan Suhu $28-25^{\circ} \mathrm{C}$ 
Dari tabel 4.6 dan gambar 4.8 terlihat suhu kandang dapat terjaga antara kisaran suhu $28{ }^{\circ} \mathrm{C}$ sampai $25{ }^{\circ} \mathrm{C}$. Hanya pada kisaran jam 12.00 WIB siang suhu kandang mencapai suhu 28.4 ${ }^{\circ} \mathrm{C}$. Hal ini disebabkan besarnya nilai suhu lingkungan sangat mempengaruhi suhu pada kandang sehingga kipas tidak dapat menjaga suhu kandang pada besaran nilai suhu yang ditentukan. Lampu akan secara otomatis hidup saat suhu kandang berada dibawah suhu $25{ }^{\circ} \mathrm{C}$ dan lampu akan mati secara otomatis ketika suhu mencapai nilai suhu diatas $27{ }^{\circ} \mathrm{C}$. Sedangkan kipas akan hidup secara otomatis hidup saat suhu kandang berada diatas suhu $28{ }^{\circ} \mathrm{C}$ dan akan mati secara otomatis ketika suhu mencapai nilai suhu $27{ }^{\circ} \mathrm{C}$.

\section{d. Batasan Suhu 27-30}

Tabel 4.7. Hasil Pengukuran Suhu Dengan Batasan Suhu $30-27{ }^{\circ} \mathrm{C}$

\begin{tabular}{|c|c|c|c|}
\hline $\begin{array}{c}\text { Pukul } \\
\text { (WIB) }\end{array}$ & $\begin{array}{c}\text { Suhu } \\
\text { Lingkungan }\left({ }^{\circ} \mathrm{C}\right)\end{array}$ & $\begin{array}{c}\text { Suhu Kandang } \\
\left({ }^{\circ} \mathrm{C}\right)\end{array}$ & Keterangan \\
\hline 00.00 & 26 & 29.4 & Lampu Hidup \\
\hline 03.00 & 24.5 & 29.4 & Lampu Hidup \\
\hline 06.00 & 26.5 & 29.4 & Lampu Hidup \\
\hline 09.00 & 28 & 27.9 & - \\
\hline 12.00 & 31,2 & 28.9 & Kipas Hidup \\
\hline 15.00 & 29.4 & 29.4 & - \\
\hline 18.00 & 28.4 & 27.9 & Kipas Hidup \\
\hline 21.00 & 27 & 29.4 & Lampu Hidup \\
\hline
\end{tabular}

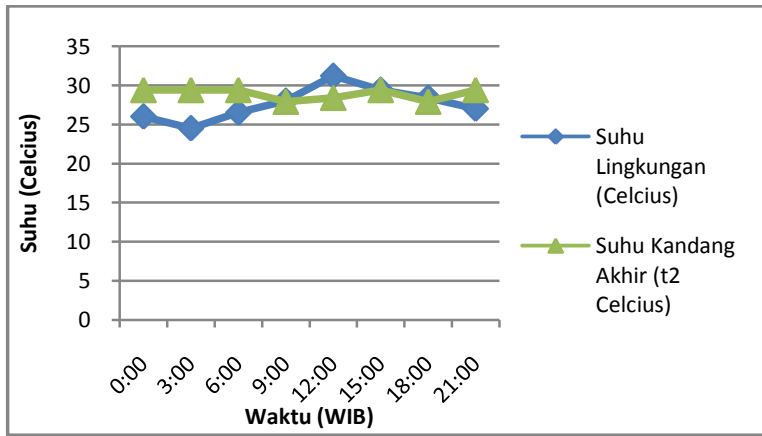

Gambar 4.9 Grafik Hasil Pengukuran Suhu Dengan Batasan Suhu $30-27{ }^{\circ} \mathrm{C}$

Dari tabel 4.7 dan gambar 4.9 terlihat suhu kandang dapat terjaga antara kisaran suhu $30{ }^{\circ} \mathrm{C}$ sampai $27{ }^{\circ} \mathrm{C}$. Suhu kandang dapat terjaga dengan baik sesuai dengan batasan suhu yang sudah ditentukan. Lampu akan secara otomatis hidup saat suhu kandang berada dibawah suhu 27 ${ }^{\circ} \mathrm{C}$ dan lampu akan mati secara otomatis ketika suhu mencapai nilai suhu diatas $29{ }^{\circ} \mathrm{C}$. Sedangkan kipas akan hidup secara otomatis hidup saat suhu kandang berada diatas suhu 30 ${ }^{\circ} \mathrm{C}$ dan akan mati secara otomatis ketika suhu mencapai nilai suhu $29{ }^{\circ} \mathrm{C}$. e. Batasan Suhu 29-32

Tabel 4.8. Hasil Pengukuran Suhu Dengan Batasan Suhu 32 - 29 C

\begin{tabular}{|c|c|c|c|}
\hline $\begin{array}{c}\text { Pukul } \\
(\text { WIB })\end{array}$ & $\begin{array}{c}\text { Suhu } \\
\text { Lingkungan }\left({ }^{\circ} \mathrm{C}\right)\end{array}$ & $\begin{array}{c}\text { Suhu Kandang } \\
\left({ }^{\circ} \mathrm{C}\right)\end{array}$ & Keterangan \\
\hline 00.00 & 26 & 29.4 & Lampu Hidup \\
\hline 03.00 & 24.5 & 29.4 & Lampu Hidup \\
\hline 06.00 & 26.5 & 29.4 & Lampu Hidup \\
\hline 09.00 & 28 & 27.9 & - \\
\hline 12.00 & 31,2 & 28.9 & Kipas Hidup \\
\hline 15.00 & 29.4 & 29.4 & - \\
\hline 18.00 & 28.4 & 27.9 & Kipas Hidup \\
\hline 21.00 & 27 & 29.4 & Lampu Hidup \\
\hline
\end{tabular}

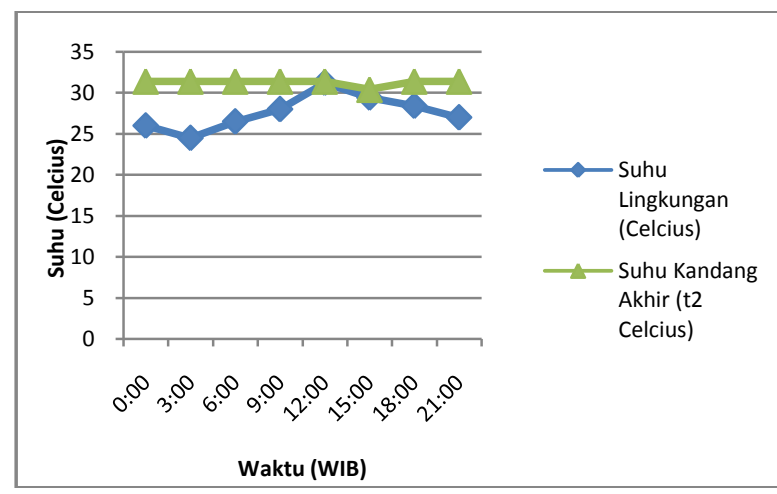

Gambar 4.10 Grafik Hasil Pengukuran Suhu Dengan Batasan Suhu $32-29^{\circ} \mathrm{C}$

Dari tabel 4.8 dan gambar 4.10 terlihat suhu kandang dapat terjaga antara kisaran suhu $32{ }^{\circ} \mathrm{C}$ sampai $29{ }^{\circ} \mathrm{C}$. Suhu kandang dapat terjaga dengan baik sesuai dengan batasan suhu yang sudah ditentukan. Lampu akan secara otomatis hidup saat suhu kandang berada dibawah suhu 29 ${ }^{\circ} \mathrm{C}$ dan lampu akan mati secara otomatis ketika suhu mencapai nilai suhu diatas $31{ }^{\circ} \mathrm{C}$. Sedangkan kipas akan hidup secara otomatis hidup saat suhu kandang berada diatas suhu 32 ${ }^{\circ} \mathrm{C}$ dan akan mati secara otomatis ketika suhu mencapai nilai suhu $31{ }^{\circ} \mathrm{C}$.

\section{SIMPULAN DAN SARAN}

\subsection{Simpulan}

Dari pembahasan dan analisis pada bab-bab sebelumnya, dapat disimpulkan bahwa:

1. Perancangan pengaturan suhu kandang ayam secara otomatis berjalan dengan baik karena alat dapat bekerja dan menjaga kestabilan suhu sesuai dengan batasan suhu yang telah ditentukan.

2. Waktu terlama yang dibutuhkan untuk menaikkan suhu kandang ayam sebesar $31^{\circ} \mathrm{C}$ 
bernilai 995 detik pada pagi hari, sedangkan yang tercepat 190 detik pada siang hari.

3. Semakin besar suhu lingkungan maka semakin cepat waktu untuk menaikkan suhu kandang, atau sebaliknya semakin kecil suhu lingkungan maka semakin lama waktu untuk menaikkan suhu kandang.

\subsection{Saran}

Adapun saran dari penelitian ini adalah sebagai berikut :

1. Menggunakan fan/kipas AC sebagai penurun suhu kandang ayam, karena pada pengujiannya kipas/ fan DC sedikit lambat dalam menurunkan suhu kandang .

2. Dapat ditambahkan pengukuran kelembaban, untuk mengetahui pengaruh kipas terhadap kelembaban udara kandang ayam.

\section{DAFTAR PUSTAKA}

[1] Rasyaf, Muhammad. 2008. Panduan Beternak Ayam Pedaging. Jakarta : Penerbit Penebar Swadaya.

[2] Delima, Mira., Sugito. 2009. Dampak Cekaman Panas Terhadap Pertambahan Bobot Badan Rasio Heterofil-Limfosit dan Suhu Tubuh Ayam Broiler. Universitas Syiah Kuala. Aceh.

[3] Soebhakti, Hendawan. 2007. Basic AVR Mikrokontroler Tutorial. Polikteknik Batam. Batam.

[4] Bayu, H.S. 2012. Pemrograman Mikrokontroler dengan Bahasa C. Penerbit Andi. Yogyakarta.

[5] Rangkuti, S. 2011. Mikrokontroller ATMEL $A V R$. Penerbit Informatika. Bandung.

[6] Adiwinarto, Gatot. 2005. Penampilan danLaju Pertumbuhan Relatif Karkas dan Komponen Karkas Dua Strain Ayam Broiler Fase Finisher (21-42 Hari) Dalam Berbagai Suhu Pemeliharaan. Universitas Diponegoro. Semarang.

[7] Riza, Faishol. 2011. Perancangan Sistem Pengendali Suhu dan Memonitoring Kelembaban Berbasis Atmega8535 pada Plant Inkubator. Universitas Diponegoro. Semarang.
[8] Malvino,Albert, Paul.1984. Prinsip-Prinsip Elektronika. PenerbitErlangga. Jakarta. 